\title{
PERILAKU PETERNAK TERHADAP PENYULUHAN \\ PEMBUATAN BIOGAS DI KELOMPOK TANI KARYA \\ MAKMUR II DI DESA WONOREJO KECAMATAN LAWANG \\ KABUPATEN MALANG
}

\section{FARMER'S BEHAVIOUR TOWARDS THE EXTENSION OF BIOGAS MANUFACTURE IN MAKMUR II FARMER GROUP IN WONOREJO VILLAGE LAWANG SUBDISTRICT MALANG REGENCY}

\author{
Alfred Adoe ${ }^{1}$, Hananik Prasetyo ${ }^{2}$, Dewi R. Ayu Daning ${ }^{3}$ \\ ${ }^{1}$ Balai Besar Pelatihan Peternakan (BBPP) Kupang \\ ${ }^{2,3}$ Sekolah Tinggi Penyuluhan Pertanian (STPP) Malang \\ Email : alfredadoe143@gmail.com
}

\begin{abstract}
ABSTRAK
Penelitian ini bertujuan untuk merancang dan membuat biogas dari kotoran ternak sapi potong, menyusun rancangan penyuluhan tentang pembuatan biogas dari kotoran ternak sapi potong lebih lanjut untuk mengetahui perilaku peternak terhadap penyuluhan pembuatan biogas dari kotoran ternak sapi potong, yang dilaksanakan di Kelompok Tani Karya Makmur II Desa Wonorejo Kecamatan Lawang Kabupaten Malang, pada tanggal 05 Maret sampai dengan 01 Juni 2018. Metode penelitian yang digunakan adalah deskriptif kuantitatif dimana data yang digunakan adalah data primer dan sekunder. Pengumpulan data menggunakan wawancara, observasi dan penyebaran kuesioner. Populasi yang diambil adalah 63 orang dengan penentuan sampel menggunakan purposive sampling dan ditetapkan 30 responden. Data yang dikumpulkan dianalisis menggunakan statistik deskriptif. Hasil penelitian menunjukan bahwa (1) Pembuatan digester biogas skala rumah tangga menggunakan drum besi yang menghasilkan gas selama 2,45 jam/hari sebagai kebutuhan energi bahan bakar rumah tangga. (2) Rancangan penyuluhan meliputi penyusunan sasaran, tujuan, materi, metode, media dan evaluasi yang disesuaikan dengan karakteristik responden. (3) Sebagian besar sasaran penyuluhan memiliki perilaku yang positif dimana pengetahuan sasaran terbanyak berada pada dimensi "tahu" dengan kategori tinggi 28 orang dan kategori sedang 2 orang. Sikap sasaran menerima penyuluhan pembuatan biogas dan keterampilan sasaran berada pada dimensi "menirukan" dengan kategori tinggi 13 orang dan kategori sedang 17 orang.
\end{abstract}

Kata Kunci : Penyuluhan, Biogas, Kotoran Ternak, Perilaku

\section{ABSTRACT}

This research us aimed to design and manufacture biogas from cattle waste and to compile extension design about how to manufacture biogas from cattle waste furthermore to know the behaviour of farmer from extension result in Karya Makmur II Farmer Group Wonorejo Village Lawang Sub-District Malang District, from March 05 to June 01 2018. This research method using descriptive quantitative where the data used are primary and secondary data. Data collection using interviews, observation and distribution of questionnaires. The 117 | Jurnal Agriekstensia Vol. 17 No. 2 Tahun 2018 
population taken are 63 people with sample determination using purposive sampling and determined 30 respondents. The data collected were analyzed using descriptive statistics. The results showed that (1) Preparation of household-scale biogas digester using an iron drum that produces gas for 2.45 hours a day as household fuel energy needs. (2) The draft of extension involves the preparation of objectives, target objectives, materials, methods, media and evaluations that are tailored to the characteristics of the respondents. (3) Most of the outreach targets have positive behaviors in which the most targeted knowledge is in the "know" dimension with a high category of 28 people and moderate category 2 people. The target attitudes received biogas production extension and targeted skills were in the "mimicking" dimension with high category 13 people and moderate category 17 people.

\section{Key Word: Extension, Biogas, Feces, Behaviour}

\section{PENDAHULUAN}

Kecamatan Lawang terdiri dari 2 kelurahan dan 10 desa, dengan luas lahan 3.655,66 Ha, jumlah penduduk 108.502 jiwa. Masyarakat Kecamatan Lawang memiliki mata pencaharian cukup berimbang di beberapa sektor, dimana terdapat 14.494 orang disektor perdagangan, dan 4.825 orang bermata pencaharian di sektor pertanian dan peternakan (Anonim, 2017).

Peternakan memiliki potensi cukup besar dengan jumlah ternak besar dan kecil sebanyak 170.259 ekor. Jumlah ini terdiri dari ternak sapi potong, 8.964 ekor, sapi perah, 2.266 kambing, 4.714 ekor yang dipelihara secara intensif. Bidang pertanian juga mempunyai potensi yang sangat besar, hal ini dilihat dari lahan tanaman pangan dan hortikultura dengan luas lahan sawah 655,05 ha, dan lahan kering dengan luas 3.000,61 ha yang tersebar di 2 kelurahan dan 10 desa (Anonim, 2017). Menurut Sudaryono (2012) Kegiatan peternakan dapat dipastikan akan memberikan dampak positif sekaligus negatif. Dampak positif berupa peningkatan pendapatan peternak, perluasan kesempatan kerja, dan peningkatan ketersediaan pangan. Namun apabila tidak dikelola dengan tepat akan menimbukan permasalahan lingkungan, yaitu berupa limbah padat, udara dan cair, seperti feses, urine, sisa makanan, dan udara.

Menurut wahyuni (2009: 29) Ternak sapi yang mempunyai bobot badan $450 \mathrm{~kg}$ limbah berupa kotoran dan urine kurang lebih $25 \mathrm{~kg}$ per ekor per hari. Jika melihat 118 | Jurnal Agriekstensia Vol. 17 No. 2 Tahun 2018 dari populasi usaha ternak sapi potong yang terdapat di kecamatan Lawang sebanyak 8.964 ekor dengan rata-rata produksi limbah kotoran sebanyak $25 \mathrm{~kg}$ per ekor per hari, maka produksi limbah kotoran ternak sapi untuk keseluruhan wilayah kecamatan lawang mencapai $224.100 \mathrm{~kg} /$ hari. Melihat potensi limbah kotoran ternak sapi yang ada maka sangat mendukung untuk dimanfaatkan menjadikan biogas sebagai bahan bakar kebutuhan rumah tangga petani/ masyarakat setempat. Keunggulan dari pembuatan biogas dari limbah kotoran sapi potong adalah dapat menjadi bahan bakar energi untuk kebutuhan rumah tangga dan menekan biaya pengeluaran petani dalam pembelian bahan bakar minyak tanah atau gas LPG untuk kebutuhan sehari-hari, limbah dari pembuangan digester biogas dapat secara langsung dijadikan pupuk organik untuk tanaman atau lahan pertanian, serta mencegah terjadinya pencemaran lingkungan di Kecamatan Lawang.

Penyuluhan pertanian adalah satu proses pembelajaran bagi pelaku utama serta pelaku usaha agar mereka mau dan mampu menolong dan mengorganisasikan dirinya dalam mengakses informasi pasar, teknologi permodalan dan sumber daya lainnya, sebagai upaya peningkatan produktivitas, efisiensi usaha, pendapatan dan kesejahteraan, serta meningkatkan kesadaran dalam pelestarian fungsi lingkungan hidup (Anonim 2006). Penyuluhan dalam arti luas adalah ilmu sosial yang mempelajari sistem dan proses perubahan pada individu serta 
masyarakat agar dapat terwujud perubahan yang lebih baik sesuai dengan yang di harapkan (Setiana, 2005).

Kotoran ternak sapi potong yang belum dimanfaatkan secara optimal menjadi dasar dan acuan untuk menyusun Rancangan Penyuluhan Pembuatan Biogas dari Kotoran Ternak Sapi potong" di Kecamatan Lawang untuk merubah perilaku, yaitu pengetahuan, keterampilan dan sikap petani/ peternak agar mau dan mampu pemanfaatan limbah ternak menjadi bahan bakar biogas.

\section{METODE PENELITIAN}

Penyuluhan dilaksanakan di Kelompok Tani Karya Makmur II Desa Wonorejo Kecamatan Lawang Kabupaten Malang. Sebelum pelaksanaan penyuluhan terlebih dahulu peneliti melakukan pemantapan materi tentang pembuatan biogas di instalasi ternak besar STPP Malang pada 10 Februari 2018.

\section{Alat dan Bahan Pembuatan Biogas}

Alat yang digunakan pada kaji terap ini yaitu instalasi (digester) biogas berupa : Drum besi 1 buah, plastik untuk penampung biogas, pipa besi 3", pipa besi $1 / 2$ ", selang 3/4",selang 1,2", selang 1", sambungan lurus $1 / 2$ inci, sambungan $\mathrm{T}$, lem rajawali, stop kran, dan gergaji besi. Lakban. Alat untuk instalasi ke kompor yaitu selang gas, katup atau kran gas, Adityawarman, dkk. (2015).

Analisis Biaya Pembuatan Digester

\begin{tabular}{llrr}
\hline Alat dan Bahan & Satuan & \multicolumn{1}{c}{$\begin{array}{c}\text { Harga } \\
\text { (Rp) }\end{array}$} & \multicolumn{1}{c}{$\begin{array}{c}\text { Jumlah } \\
\text { (Rp) }\end{array}$} \\
\hline $\begin{array}{l}\text { Drum besi } \\
\text { Plastik tabung }\end{array}$ & 1 buah & 120.000 & 120.000 \\
gas & & 3.000 & 9.000 \\
Pipa besi 3" & 1 meter & 25.000 & 25.000 \\
Pipa besi 1/2” & 1 meter & 7.000 & 7.000 \\
Biaya las & 4 bagian & 150.000 & 150.000 \\
Selang 1/2” & 10 meter & 7.500 & 75.000 \\
Selang 3/4” & 5 meter & 7.500 & 37.500 \\
Paralon 1/2” & 1 meter & 10.000 & 10.000
\end{tabular}

\begin{tabular}{llrr} 
Selang 1” & 1 meter & 10.000 & 10.000 \\
Stop kran & 2 buah & 12.000 & 24.000 \\
Gergaji besi & 1 buah & 5.000 & 5.000 \\
Lem pipa & 1 buah & 7.000 & 7.000 \\
Klem pipa & 8 buah & 3.000 & 24.000 \\
\hline
\end{tabular}

Total

Langkah-langkah pembuatan digester: Posisi drum direbahkan, kedua sisi drum dilubangi dan dipasang saluran pengisian dan saluran pembuangan menggunakan pipa besi 3" (dim) dengan kemiringan 45 derajat. Ukuran pipa pengisian $120 \mathrm{~cm}$, pipa pengisian pada bagian dalam digester $75 \mathrm{~cm}$ (posisi ujung pipa berada pada bagian bawah digester) dan panjang pipa pengisian bagian luar digester $45 \mathrm{~cm}$. Ukuran pipa pembuangan $40 \mathrm{~cm}$ dengan posisi bagian dalam digester $5 \mathrm{~cm}$ dan panjang pipa bagian luar digester $35 \mathrm{~cm}$. Pada sisi bagian atas digester dibuat saluran gas menggunakan pipa besi $10 \mathrm{~cm}$ dengan ukuran pipa 1,5 " (dim). Pemasangan pipa saluran pengisian, pembuangan dan saluran biogas menggunakan las karbit. Pemasangan saluran gas dari digester ke penampung biogas menggunakan selang 1 " (dim), panjang selang 5 meter, dan pada bagian ini perlu dipasang stop kran, dengan tujuan untuk dapat mengontrol biogas bila digester dibersihkan. Saluran biogas dari penampung ke kompor menggunakan selang 1,5", panjang selang sesuaikan dengan jarak penampung gas dan kompor gas. Sasaran penyuluhan dilibatkan langsung dalam proses pembuatan instalasi digester biogas, pencampuran bahan adonan dan pengisian bahan ke dalam digester. Tahapan pembuatan digester pada uji coba penyuluhan kaji terap di adakan pengamatan (observasi) keterampilan sasaran oleh peneliti.

Pengisian awal bahan adonan atau kotoran ternak sapi dan air yang sudah dicampur dengan perbandingan (1:1) sebanyak $75-80 \%$ dari daya tampung 
digester, sehingga memberikan ruang kosong minimal $20 \%$ untuk ruang produksi gas. Menurut Adityawarman, dkk. (2015) Perbandingan Kotoran sapi dengan air (1:1), dicampur hingga berbentuk bubur dan dimasukan ke dalam digester, lama proses fermentasi untuk menghasilkan biogas selama 15 hari dan biogas dapat dipakai untuk pembakaran kompor gas atau ditampung dalam kantung penampung biogas. setelah mengeluarkan biogas dari digester, dilakukan penambahan ulang bahan sebanyak $10 \%$ dari daya tampung digester untuk proses pembentukan biogas selanjutnya. Setelah di isi kotoran sapi segar lewat tempat pengisian (inlet), akan ada sedikit bahan (kotoran sapi) yang keluar melalui lubang pembuangan (outlet).

Uji coba penggunaan biogas dilakukan 2 (dua) tahap yaitu pada hari ke 5 dan hari ke 20 sebelum diadakan penyuluhan lanjutan bersama sasaran. Tahap pertama dilakukan pada hari ke 5 namun api yang dihasil belum sempurna dan uji coba menyalakan dilakukan tahap ke 2 pada hari ke 20 dan hasil dari biogas tersebut sudah cukup sempurna karena warna api yang hasilkan berwarna biru dan tidak terdapat bau feses sapi. Biogas yang dihasilkan dalam penelitian ini $\leq 1,8 \mathrm{~m}^{3}$ karena dapat dinyalakan selama 2,45 jam. Menurut Adityawarman, dkk. (2015) Pada saat produksi gas maksimal (hari ke-20) proses pengisian digester dilakukan secara berkelanjutan sebanyak $20 \mathrm{~kg}$ (10 kg feses dan $10 \mathrm{~kg}$ air) dilakukan sebanyak 2 kali setiap harinya. Biogas yang dihasilkan dari $20 \mathrm{~kg}$ feses yang digunakan sebanyak $1.8 \mathrm{~m} 3$ setara dengan $0.736 \mathrm{~kg}$ gas LPG dan 1 liter minyak tanah. Tiap sapi mampu menghasilkan kotoran $20 \mathrm{~kg}$ per hari yang dapat menghasilkan biogas sebanyak 1$1.2 \mathrm{~m} 3$ dan dapat memenuhi kebutuhan memasak selama $2.32-2.78$ jam.

\section{Penentuan Sasaran Penyuluhan}

Sasaran dalam uji coba penyuluhan yaitu, anggota Kelompok tani Karya Makmur II dengan memiliki 12 ekor ternak 120 | Jurnal Agriekstensia Vol. 17 No. 2 Tahun 2018 sapi potong milik kelompok dan jumlah anggota keseluruhan 63 orang. Penentuan responden dengan menggunakan teknik purposive sampling dengan kriteria dan pertimbangan tertentu. Berdasarkan kriteria diatas yang layak dijadikan sasaran atau responden berjumlah 30 orang.

\section{Rancangan Penyuluhan \\ Lokasi dan Waktu}

Pelaksanaan penyuluhan dilaksanakan pada hari Rabu tanggal 18 April tahun 2018 pukul 13.30 wib sampai selesai. bertempat di rumah pak Warmudji selaku Anggota Kelompok Tani Karya Makmur II dan kandang instalasi ternak sapi potong milik Kelompok Tani Karya Makmur II.

\section{Tujuan Penyuluhan}

Tujuan yang ingin dicapai dalam penyuluhan adalah perubahan perilaku petani ternak terhadap pembuatan biogas dari kotoran ternak sapi potong sebagai energi bahan bakar kebutuhan rumah tangga.

\section{Materi Penyuluhan}

Materi penyuluhan adalah pembuatan biogas dari kotoran ternak sapi potong. Materi yang di suluhkan sebagai berikut:

Ceramah dan Diskusi

1) Pengertian biogas

2) Pembuatan instalasi reaktor (digester biogas)

3) Jenis kotoran sapi potong yang digunakan

4) Cara pencampuran feses dan air dan pengisian bahan ke dalam digester

5) Cara pemakaian biogas dan prosedur pengisian ulang feses dan air pada digester

6) Faktor-faktor yang mempengaruhi keberhasilan produksi biogas

Demonstrasi cara dan Kaji terap

1) Pembuatan Digester biogas

2) Pembuatan instalasi saluran dan penampung biogas

3) Pencampuran kotoran sapi dan air 
4) Pengisian bahan adonan ke dalam digester

5) Pengamatan biogas yang dihasilkan

6) Aplikasi pemakaian biogas

7) Pengisian ulang feses dan air.

\section{Metode, Media dan Evaluasi Penyuluhan}

Peran metode sangat penting dalam proses komunikasi penyuluhan dan menetukan keberhasilan dari proses penyuluhan itu sendiri (Warnaen ,dkk., 2017). Metode yang digunakan dalam penyuluhan melalui pendekatan kelompok. Teknik penyuluhan menggunakan ceramah, diskusi dan demonstrasi cara dan kaji terap. Media penyuluhan yang digunakan adalah video, Powerpoint, folder dan media sesungguhnya. Alat bantu yang digunakan Laptop dan LCD. Pelaksanaan evaluasi penyuluhan untuk mengetahui pengetahuan dan sikap sasaran dilakukan setelah penyuluhan dengan menggunakan metode pendekatan individu (door to door) dan pelaksanaan pengamatan (observasi) keterampilan sasaran dilakukan bertepatan dengan pelaksanaan kaji terap penyuluhan tahap pertama dan pelaksanaan pada tahap ke dua dengan penilaian secara individu terhadap sasaran. Lembar observasi dipergunakan untuk menilai keterampilan responden dalam pembuatan biogas dari kotoran ternak sapi potong.

\section{Metode Pengumpulan Data}

Metode pengumpulan data yang digunakan dalam kajian ini adalah metode survei dan kuesioner. Pengumpulan data dilakukan dengan menggunakan dua jenis sumber data yaitu data primer dan data sekunder. Setelah data terkumpul dilakukan uji validitas dan reliabilitas kuesioner, alat ukur yang digunakan untuk mengukur validitas adalah rumus Pearson Product Moment (Riduwan dan Kuncoro, 2012 : 217) dan uji reliabilitas menggunakan rumus korelasi Product Moment (Riduwan dan Kuncoro,2012 : 222).

\section{Pengolahan Data Perilaku}

121 | Jurnal Agriekstensia Vol. 17 No. 2 Tahun 2018
Pengolahaan data menggunakan analisis deskriptif, dengan pengumpulan data dan peringkasan data yang dapat disajikan dalam bentuk tabel sebagai dasar pengambilan keputusan (Santoso, 2014). Selanjutnya diolah melalui tahapan berikut : 1) Editing yakni meneliti kebenaran data yang diperoleh. 2) Coding yakni jawaban responden diberi skor. 3) Tabulasi dengan menggunakan perhitungan statistik dan perhitungan matematika. Analisis deskriptif untuk menerangkan dan menjelaskan kajian tingkat perubahan perilaku peternak tentang pembuatan biogas dari limbah kotoran ternak sapi potong.

\section{Pengukuran Pengetahuan}

Pelaksanaan evaluasi penyuluhan untuk mengetahui tingkat pengetahuan petani dilakukan melalui tes awal dan tes akhir dengan menggunakan alat ukur kuesioner, untuk mencapai tujuan pengkajian melalui perangkingan skoring tertinggi. Menurut Permentan Nomor 91 Tahun 2013 standar nilai prestasi dapat diketahui dengan syarat:

1. Jumlah pengukuran/parameter sebanyak 16, setiap indikator dinilai dengan menggunakan skala 1 sampai sampai dengan 5. Skala 1 menunjukan nilai paling rendah dan skala 5 menunjukan nilai paling tinggi.

2. Jumlah nilai seluruh pengukuran/parameter yaitu paling rendah $16 \quad$ jumlah pengukuran/parameter $=16 \times 1)$ dan paling tinggi 80 (jumlah pengukuran/parameter $=\quad 16 \times 5) . \quad$ Jumlah nilai pengukuran/parameter yang diperoleh disebut NEM merupakan ukuran prestasi.

3. Standar nilai prestasi dinyatakan dalam angka dan sebutan sebagai berikut:

$$
\begin{array}{ll}
76-100 & =\text { Tinggi } \\
48-75 & =\text { Sedang } \\
20-47 & =\text { Rendah }
\end{array}
$$

Tata cara perhitungan:

$$
\text { Nilai prestasi }=\frac{\text { Total } N E M}{80} \times 100
$$




\section{Pengukuran Sikap}

Pengukuran sikap menggunakan 20 item pernyataan, terdirir dari 4 dimensi. Kaidah keputusan untuk tingkat pengukuran sikap responden dengan pilihan (SS) Sangat setuju skor 4, (S) Setuju skor 3, (TS) Tidak setuju skor (2), dan (STS) Sangat tidak setuju skor 1. Setelah dilakukan rekapitulasi nilai dari jawaban responden atas pernyataan dan ditabulasi.

Rumus perhitungan:

- Skor terendah $\mathrm{x}$ jumlah item $=$ Nilai terendah

- Skor tertinggi $\mathrm{x}$ jumlah item = Nilai tertinggi

Tingkat sikap terdiri 2 kategori.

Maka: Skor terendah : 1 x $20=20$

Skor tertinggi : 4 × $20=80$

Kelas Interval:

$$
\frac{80-20}{2}=30
$$

Kaidah keputusan untuk tingkat sikap responden:

$51-80=$ Menerima

$20-50=$ Menolak

\section{Pengukuran Keterampilan}

Mengukur keterampilan responden tentang penyuluhan pembuatan biogas menggunakan skala model rating scale. Indikator penilaian dalam lembar observasi untuk mengukur tingkat keterampilan responden berjumlah 20 item.

Skor penilaian Pemberian skor keterampilan menggunakan angka 5 (Terampil), 3 (cukup terampil), 1 (Tidak terampil). Untuk mengkategorikan keterampilan responden adalah sebagai berikut:

- Skor terendah $\mathrm{x}$ jumlah item $=$ Nilai terendah

- Skor tertinggi $\mathrm{x}$ jumlah item = Nilai tertinggi

Tingkat keterampilan terdiri 3 kategori.

Maka : Skor terendah : 1 x $20=20$

Skor tertinggi : 5 x $20=100$

$$
\text { Kelas Interval }=\frac{100-20}{3}=27
$$

122 | Jurnal Agriekstensia Vol. 17 No. 2 Tahun 2018
Kaidah keputusan untuk tingkat keterampilan responden:

$$
\begin{array}{ll}
76-100 & =\text { Terampil } \\
48-75 & =\text { Cukup terampil } \\
20-47 & =\text { Tidak terampil }
\end{array}
$$

Tata cara perhitungan:

$$
\text { Nilai prestasi } i=\frac{\text { Total } N E M}{80} \times 100
$$

\section{HASIL DAN PEMBAHASAN}

\section{Nilai Pre Test Pengetahuan}

Hasil rekapitulasi pre test tingkat pengetahuan sasaran penyuluhan merancang dan membuat biogas dari kotoran ternak sapi potong, distribusi berdasarkan teori taksonomi bloom dari C1 sampai dengan C6 dapat dilihat pada tabel dibawah ini.

Tabel 1. Distribusi Pre Test Pengetahuan Sasaran

\begin{tabular}{ccccccc}
\hline \multirow{2}{*}{ Kategori } & \multicolumn{7}{c}{ Pre Test } \\
\cline { 2 - 7 } & C1 & C2 & C3 & C4 & C5 & C6 \\
\hline Tinggi & - & - & - & - & - & - \\
Sedang & 19 & 17 & 15 & 15 & 13 & 13 \\
Rendah & 11 & 13 & 15 & 15 & 17 & 17 \\
\hline Jumlah & 30 & 30 & 30 & 30 & 30 & 30 \\
\hline Sumber: Data Primer yang Diolah, 2018.
\end{tabular}

Tabel diatas menunjukan hasil pre test pengetahuan per dimensi dari 30 sasaran sebagai berikut:

a) $\mathrm{C} 1$ (tahu) terdapat 3 (tiga) butir pernyataan. Jawaban tertinggi berjumlah 19 orang berada pada kategori sedang, dan 11 orang berada pada kategori rendah. Butir pernyataan tertinggi pada dimensi $\mathrm{C} 1$ berada pada butir pernyataan pertama dengan kategori pengetahuan sedang 22 orang, kategori rendah 7 orang dan kategori tinggi 1 orang.

b) C2 (Paham) terdapat 1 (satu) butir pernyataan. Jawaban tertinggi berjumlah 17 orang berada pada kategori sedang, dan 13 orang berada pada kategori rendah. 

(Alfred Adoe, Hananik P., dan Dewi R.A.Daning)

c) C3 (Aplikasi) terdapat 5 (lima) butir pernyataan. Jawaban kategori sedang 15 orang dan kategori rendah 15 orang.

d) C4 (Analisis) terdapat 2 (dua) butir pernyataan. Jawaban kategori sedang 15 orang dan kategori rendah 15 orang.

e) C5 (Evaluasi) terdapat 4 (empat) butir pernyataan. Jawaban kategori sedang 13 orang dan kategori rendah 17 orang.

f) C6 (Kreasi) terdapat 5 (lima) butir pernyataan. Jawaban kategori sedang 13 orang dan kategori rendah 17 orang.

Hasil perhitungan pre test pengetahuan per dimensi tertinggi berada pada dimensi C1 (Tahu), dengan kategori pengetahuan "sedang" berjumlah 19 orang dan kategori pengetahuan "rendah" 11 orang. Diikuti dengan dimensi C2 (paham) dan terendah berada pada dimensi C5 (evaluasi) dan C6 (kreasi). Diduga hasil tersebut terjadi karena sasaran pernah mendapatkan informasi tentang pembuatan biogas, namun belum pernah mempraktekan pembuatan biogas secara langsung sehingga pengetahuan sasaran masih berada pada ranah tahu dan paham.

Berdasarkan alasan diatas maka perlu diadakan suatu pembelajaran melalui rancangan penyuluhan demi meningkatkan pengetahuan, sikap dan keterampilan sasaran dalam memanfaatkan potensi limbah kotoran ternak yang ada sebagai bahan bakar kebutuhan rumah tangga.

\section{Pengetahuan Sasaran}

Hasil rekapitulasi post test tingkat pengetahuan sasaran setelah pelaksanaan penyuluhan merancang dan membuat biogas dari kotoran ternak sapi potong, distribusi berdasarkan teori taksonomi bloom dari $\mathrm{C} 1$ sampai dengan C6 sebagai berikut:

Tabel 2. Distribusi Post Test Pengetahuan

\begin{tabular}{ccccccc}
\multicolumn{6}{c}{ Pasaran } \\
\cline { 2 - 7 } Nilai & Pre Test \\
Kategori & C1 & C2 & C3 & C4 & C5 & C6
\end{tabular}

$\begin{array}{lllllll}\text { Tinggi } & 28 & 7 & 7 & 12 & 15 & 17\end{array}$

123 | Jurnal Agriekstensia Vol. 17 No. 2 Tahun 2018

\begin{tabular}{ccccccc} 
Sedang & 2 & 23 & 23 & 16 & 14 & 10 \\
Rendah & - & - & - & 2 & 1 & 3 \\
\hline Jumlah & 30 & 30 & 30 & 30 & 30 & 30 \\
\hline
\end{tabular}

Sumber: Data Primer yang Diolah, 2018.

Tabel diatas menunjukan hasil post test pengetahuan per dimensi dari 30 sasaran sebagai berikut:

a) C1 (Tahu) terdapat 3 (tiga) butir pernyataan. Pengetahuan sasaran meningkat menjadi 28 orang berada pada kategori "tinggi" dan 2 orang berada pada kategori "sedang". Butir pernyataan tertinggi pada dimensi $\mathrm{C} 1$ berada pada butir pernyataan pertama dengan kategori pengetahuan "tinggi" 28 orang, kategori "sedang" 2 orang.

b) C2 (Paham) terdapat 1 (satu) butir pernyataan. Jawaban kategori "tinggi" berjumlah 7 orang, dan kategori "sedang" sebanyak 23 orang.

c) C3 (Aplikasi) terdapat 5 (lima) butir pernyataan. Jawaban kategori "tinggi" sebanyak 23 orang dan kategori "sedang" 15 orang.

d) C4 (Analisis) terdapat 2 (dua) butir pernyataan. Jawaban kategori "tinggi" sebanyak 12 orang, kategori "sedang" 16 orang dan kategori "rendah" 2 orang.

e) C5 (Evaluasi) terdapat 4 (empat) butir pernyataan. Jawaban kategori "tinggi" sebanyak 15 orang, kategori "sedang" 14 orang dan kategori "rendah" 1 orang.

f) C6 (Kreasi) terdapat 5 (lima) butir pernyataan. Jawaban kategori "tinggi" sebanyak 17 orang, kategori "sedang" 10 orang dan kategori "rendah" 3 orang.

Hasil perhitungan post test pengetahuan per dimensi tertinggi berada pada dimensi C1 (Tahu), dengan kategori pengetahuan "tinggi" berjumlah 28 orang dan kategori pengetahuan "sedang" 2 orang dari 30 sasaran. Sebelum penyuluhan dilaksanakan kategori pengetahuan sasaran tertinggi berada pada dimensi C1 (Tahu), dengan kategori pengetahuan "sedang" 19 orang dan kategori "rendah" 11 orang. 
Setelah pelaksanaan penyuluhan, kategori pengetahuan tertinggi sasaran tetap berada pada dimensi $\mathrm{C} 1$ (Tahu), namun terjadi peningkatan pengetahuan dengan kategori "tinggi" menjadi 28 orang dan kategori pengetahuan "sedang" berkurang menjadi 2 orang. Diduga hasil tersebut terjadi karena pada proses penyuluhan sasaran dilibatkan langsung pada pembuatan biogas, sehingga daya menyerapan materi yang disampaikan teradopsi dengan baik. Hal ini sesuai pendapat Mardikanto (2009:315) yang menyatakan bahwa "Alat atau benda yang dapat diamati, didengar, diraba atau dirasakan oleh manusia, yang berfungsi sebagai alat untuk meragakan dan atau uraian yang disampaikan secara lisan oleh penyuluh guna membantu proses belajar penerima manfaat penyuluhan agar materi penyuluhan lebih mudah diterima dan dipahami oleh penerima manfaat penyuluhan yang bersangkutan".

Sikap Sasaran

Sikap Sasaran terhadap penyuluhan pembuatan biogas dari kotoran ternak sapi potong menggunakan kuesioner model skala likert dan data yang didapat analisis secara statistik deskriptif. Distribusi berdasarkan teori taksonomi bloom dari A1 sampai dengan A5 dapat tabel berikut:

Tabel 3. Distribusi Sikap Sasaran

\begin{tabular}{cccccc}
\hline Kategori & A1 & A2 & A3 & A4 & A5 \\
\hline $\begin{array}{c}\text { Menerima } \\
(\geq 50)\end{array}$ & 29 & 30 & 30 & 30 & 30 \\
$\begin{array}{c}\text { Menolak } \\
(<50)\end{array}$ & 1 & - & - & - & - \\
\hline Jumlah & 30 & 30 & 30 & 30 & 30 \\
\hline
\end{tabular}

Sumber: Data Primer yang diolah, 2018.

Tabel diatas menunjukan Hasil rekapitulasi sikap sasaran penyuluhan diuraikan berdasarkan teori taksonomi bloom ada 5 (lima) dimensi, yaitu A1 (Menerima), A2 (respon), A3 (menilai), A4 (organisasi), A5 (karakterisasi). Berikut adalah hasil uraian perhitungan nilai sikap per dimensi dari A1 - A5 sebagai berikut: 124 | Jurnal Agriekstensia Vol. 17 No. 2 Tahun 2018 a) A1 (Menerima) terdapat 5 (lima) butir pernyataan dengan nilai dalam dimensi "menerima" berjumlah 29 orang dan nilai dalam dimensi "menolak" berjumlah 1 orang.

b) A2 (Respon) terdapat 3 (tiga) butir pernyataan dengan nilai dalam dimensi 'respon' berjumlah 30 orang (menerima).

c) A3 (Menilai) terdapat 4 (empat) butir pernyataan dengan nilai dalam dimensi menilai berjumlah 30 orang (menerima).

d) A4 (Organisasi) terdapat 2 (dua) butir pernyataan dengan nilai dalam dimensi "organisasi' berjumlah 30 orang (menerima).

e) A5 (Karakterisasi) terdapat 6 (tiga) butir pernyataan dengan nilai tertinggi dalam dimensi "karakteristik" berjumlah 30 orang (menerima).

Hasil perhitungan sikap sasaran per dimensi dinyatakan dapat "menerima" penyuluhan pembuatan biogas dari kotoran ternak sapi potong. Hal ini sesuai pendapat Azwar (2013:30) yang menyatakan bahwa "Diantara berbagai faktor yang mempengaruhi pembentukan sikap adalah pengalaman pribadi, kebudayaan, orang lain yang dianggap penting, media massa, institusi atau lembaga pendidikan dan lembaga agama, serta faktor emosi dalam diri individu".

\section{Keterampilan Sasaran}

Keterampilan Sasaran terhadap penyuluhan pembuatan biogas dari kotoran ternak sapi potong menggunakan kuesioner model ranting scale dan data yang didapat di analisis secara statistik deskriptif. Distribusi berdasarkan teori taksonomi bloom dari P1 sampai dengan P4 dapat dilihat pada tabel berikut:

Tabel 4. Distribusi Keterampilan Sasaran

$\begin{array}{ccccc}\begin{array}{c}\text { Nilai } \\ \text { Kategori }\end{array} & \text { P1 } & \text { P2 } & \text { P3 } & \text { P4 } \\ \text { Tinggi } & 13 & 5 & 13 & 8\end{array}$




\begin{tabular}{ccccc} 
Sedang & 17 & 17 & 17 & 17 \\
Rendah & - & 8 & - & 5 \\
\hline Jumlah & 30 & 30 & 30 & 30 \\
\hline
\end{tabular}

Sumber: Data Primer yang diolah, 2018. Tabel diatas menunjukan hasil rekapitulasi keterampilan sasaran penyuluhan berdasarkan teori taksonomi bloom ada 4 (empat) dimensi yaitu P1 (menirukan), P2 (memanipulasi), P3 (pengalamiahan), P4 (artikulasi). Uraian nilai keterampilan per dimensi dari P1 - P4 sebagai berikut:

a) P1 (Menirukan) terdapat 6 (enam) butir pernyataan dengan nilai kategori "tinggi" berjumlah 13 orang, nilai kategori "sedang" berjumlah 17 orang.

b)P2 (Memanipulasi) terdapat 6 (enam) butir pernyataan dengan nilai kategori "tinggi" berjumlah 5 orang, nilai kategori "sedang" berjumlah 17 orang dan nilai kategori "rendah" berjumlah 8 orang.

c) P3 (Pengalamiahan) terdapat 2 (dua) butir pernyataan dengan nilai kategori "tinggi" berjumlah 13 orang, nilai kategori "sedang" berjumlah 17 orang.

d) P4 (Artikulasi) terdapat 6 (enam) butir pernyataan dengan nilai kategori "tinggi" berjumlah 8 orang, nilai kategori "sedang" berjumlah 17 orang dan nilai "rendah' berjumlah 5 orang.

Hasil perhitungan keterampilan sasaran per dimensi dari dimensi P1 sampai pada $\mathrm{P} 4$, nilai tertinggi berada pada dimensi P1 (menirukan) dan P3 (pengalamiahan), dengan kategori yang sama yaitu kategori "tinggi" 13 orang dan kategori "sedang" 17 orang. Sedangkan kategori keterampilan terendah berada pada dimensi P2 (memanipulasi) dengan kategori keterampilan "tinggi" 5 orang, kategori "sedang" 17 orang dan kategori keterampilan "rendah" 8 orang dari 30 sasaran. Hal ini sejalan pendapat Mardikanto (2009:300) yang menyatakan bahwa "Metode demonstrasi cara, kaji terap dan atau hasil seringkali dipandang sebagai metode yang paling efektif. Karena kepada penerima manfaat penyuluhan perlu ditunjukkan (diragakan) bukti-bukti yang nyata, yang dapat dengan mata kepala sendiri, agar mereka mempercayai segala sesuatu yang disuluhkan".

\section{KESIMPULAN}

Kesimpulan dalam penelitian ini antara lain:

1. Digester biogas skala rumah tangga dapat dibuat menggunakan drum besi yang menghasilkan gas selama 2,45 jam per hari sebagai kebutuhan energi bahan bakar keperluan rumah tangga. Pembuangan limbah (slurry) dari digester dapat secara langsung digunakan sebagai pupuk organik untuk tanaman maupun lahan pertanian.

2. Rancangan penyuluhan pembuatan biogas dari kotoran ternak sapi potong, dalam penentuan sasaran, materi, metode dan media penyuluhan sesuai dengan karakteristik sasaran. Uji coba pelaksanaan penyuluhan, sehingga sasaran dapat menerima materi penyuluhan yang disampaikan dengan efektif.

3. Berdasarkan kesesuaian dalam penetapan rancangan uji coba penyuluhan seperti yang di uraikan diatas, maka hasil analisis perilaku yang terdiri dari pengetahuan, sikap dan keterampilan sasaran meningkat.

\section{DAFTAR PUSTAKA}

Adityawarman, Dkk. 2015. Pengolahan Limbah Ternak Sapi Secara Sederhana di Desa Pattalassang Kabupaten Sinjai Sulawesi Selatan. Jurnal Ilmu Produksi dan Teknologi Hasil Peternakan ISSN 2303-2227. [8 Desember 2017].

Anonim, 2017. Programa Penyuluhan Pertanian UPT Balai Penyuluhan Kecamatan Lawang. 
Anonim, 2017. Profil Desa Wonorejo Kecamatan Lawang Kabupaten Malang.

Anonim, 2006. Undang-undang Nomor 16 Tahun 2006 Tentang Sistem Penyuluhan Pertanian, Perikanan dan Kehutanan.

Anonimus, 2017. Sistem Informasi Desa Dan Kelurahan Direktorat Jenderal Bina Pemerintah Desa Kementerian Dalam Negeri. http:// prodeskel.binapemdes.kemendagri.go.i d/ mpublik/. [24 Mei 2018].

Anonimus, 2013 Peraturan Menteri Pertanian Nomor 91 Tahun 2013 Tentang Pedoman Evaluasi Kinerja Penyuluh Pertanian.

Azwar. 2013. Sikap Manusia Teori dan Pengukurannya. Yogyakarta: Pustaka Pelajar. [ 22 November 1017].

Mardikanto, T. 2009. Sistem Penyuluhan Pertanian. Surakarta: Lembaga Pengembangan Pendidikan (LPP) UNS dan UPT Penerbitan dan Percetakan UNS (UNS Press).

Riduwan dan Engkos Achmad Kuncoro, 2012. Cara Mudah Menggunakan dan
Memakai Path Analysis (Analisis Jalur). Bandung : Alfabeta. [23 November 2017].

Setiana, L. 2005. Teknik Penyuluhan Pertanian dan Pemberdayaan Masyarakat. Ghalia Indonesia, Bogor. [ 23 November 2017].

Sudaryono, 2012. Pemanfaatan Biogas dari Limbah Kotoran Ternak Sebagai Sumber Energi Listrik. Studi kasus di Desa Sutenjaya, Lembang, Jawa Barat. Pusat Teknologi Lingkungan Badan Pengkajian dan Penerapan Teknologi .Tangerang Selatan. [20 Januari 2018].

Wahyuni, S. 2009. Biogas. Sumber BiogasJenis Digester-Cara Mengoperasikan. Cetakan 1. Penebar Swadaya,Jakarta. [15 Desember 2017].

Warnaen, A., Nurlaili dan A.V. Sukmarini. 2017. Metode Komunikasi Penyuluhan Pertanian Melalui Radio Komunitas. Jurnal Ilmu Komunikasi Vol.8 No. 1 (2017). Universitas fajar Makassar. Download at: https://ejournal.unri.ac.id/index.php/JK MS/article/view/4231/4067 
